\title{
Publisher Correction: Exosome-eluting stents for vascular healing after ischaemic injury
}

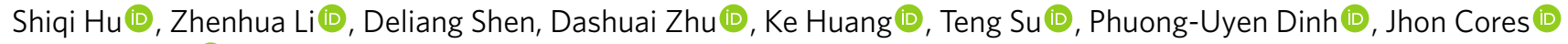
and Ke Cheng (D)

Correction to: Nature Biomedical Engineering https://doi.org/10.1038/s41551-021-00705-0, published online 5 April 2021.

The wrong Reporting Summary file was originally published for this Article; it has now been replaced with the correct file.

Published online: 20 April 2021

https://doi.org/10.1038/s41551-021-00727-8

(C) The Author(s), under exclusive licence to Springer Nature Limited 2021 